\title{
Dynamic Manufacturing Networks Monitoring and Governance
}

\author{
Panagiotis Kokkinakos, Ourania Markaki, Dimitrios Panopoulos, \\ Sotirios Koussouris, and Dimitrios Askounis \\ Greek Interoperability Center, Decision Support Systems Laboratory, School of Electrical and \\ Computer Engineering, National Technical University of Athens, Greece \\ \{pkokkinakos, omarkaki, dpano, skous, askous\} @epu.ntua.gr
}

\begin{abstract}
Monitoring and Governance" is the most important phase of every Dynamic Manufacturing Network (DMN) lifecycle and aims at managing and controlling in a continuous way the operations of the network, resulting either in "small and corrective" actions towards the network's operation optimisation or to "larger and structural" changes, which are fed back to the initial phases of the network's lifecycle, for reconstructing the network towards better results. The study at hand aims to review current approaches for controlling and monitoring plant operation or traditional supply chains, and to examine thereby their maturity and adequacy for the management and monitoring of dynamic manufacturing networks, leading to useful conclusions with regard to the requirements and challenges encountered in this particular phase of the DMN lifecycle.
\end{abstract}

Keywords: Manufacturing Network, Operations Management, Monitoring, Governance, Dynamic Manufacturing Network, DMN.

\section{Introduction}

Trying to adapt to the given and ongoing global economic crisis, the industrial/manufacturing sector pursues to minimize costs and, at the same time, to increase the effectiveness of external and internal procedures, as well as the customers' satisfaction through high quality products/services. The formation of Dynamic Manufacturing Networks (DMNs, which elsewhere and depending on the context, might also be referred as Virtual Enterprises) [2] is the natural evolution of typical supply chains that aim to respond to these challenges. DMN is a newly introduced term, coined to express the establishment of dynamic alliances among manufacturing companies in the direction of virtual enterprises for gaining mutual benefits. DMNs constitute a demand-driven (yet long-lasting) formation of enterprises for a certain purpose [1]. For this purpose, the interconnection and effective communication among the various systems of every participating enterprise is considered a precondition. This communication is not limited to systems serving the same goal (e.g. ERP systems), but includes shop floor production systems, as well as top-level management systems. The general rationale behind forming such networks is to reduce both costs and time to market, 
while increasing flexibility, gaining access to new markets and resources, and utilizing collective intelligence on methodologies and procedures. The notion of a DMN includes the configuration of a network consisting of a large number of closely integrated and interdependent projects, which are executed over a wide geographic spread, across different time zones, and involve large numbers of staff. As it is understandable, this whole process, apart from being very difficult to be performed, affects also a wide range of stakeholders whether they are members of the network or not.

Although research has delivered a lot of methodologies for controlling plant operation and for monitoring production systems' effectiveness, there are no mature methodologies and tools fully appropriate for managing and monitoring DMNs. Today, various platforms exist (e.g. Transportation Management Systems, Material Resource Planning, Warehouse Management Systems), but as Westphal et al. note [3], there is a lack of approaches and tools specifically developed for dynamic networks that consist of distributed, independent, and heterogeneous members. Current approaches cannot deliver acceptable results without strong modifications and one has to investigate to what extent they can meet the different requirements set by such dynamic alliances.

DMN Monitoring and Governance can be split in the following four sub-phases:

- Real Time Data Collection and Network Monitoring.

- Operational Level DMN Governance.

- Network Performance Measurement and KPIs Monitoring.

- Network Performance Evaluation and DMN Reformation.

The focus of this study primarily lies on the definition of appropriate methods and ICT tools supporting the efficient Monitoring and Governance of Dynamic Manufacturing Networks. The four aforementioned sub-stages are discussed and analyzed, while conclusions are drawn with respect to the whole DMN process.

\section{Real Time Data Collection and Network Monitoring}

Industries and manufacturing organizations in general constantly face the challenge of organizing, checking and monitoring their activities. Especially nowadays, where saving time and reacting as fast as possible to emergencies and changes of demand constitute vital parameters to such kind of organizations, enterprise network monitoring is becoming of outmost importance. Its main task is to support avoiding severe economic losses resulting from unexpected process failures by improving the network's reliability and maintainability [20].

Monitoring an event-driven [11] and complicated system, such as an enterprise or an industrial network, is based on real time collection, exchange and processing of information. It can be taken as granted that the processing speed, as well as the great volume of data, constitute barriers towards an effective and stable solution. However, the advances in network technology and data collection, storage and processing in the dispersed manufacturing approach and the flexible and powerful virtual enterprise approach are rapidly emerging [14]. Processes take place in several locations and new 
business opportunities can rise, both for suppliers and producers. Similar approaches can be met as performance measurement and performance management [25].

In order to overcome interoperability and data exchange problems, that are highly possible to come up in such complex procedures, a number of standards such as Product Data Exchange Specification (PDES), Standard for Exchange of Product (STEP) and Initial Graphic Exchange Specification (IGES) have been established.

The architecture of a virtual enterprise network basically consists of three layers: the network/platform layer, the service layer and the application layer. At the network level, the architecture defines the data formats and communication protocols that enable clients to exchange information and services. The service layer is a middle layer of reusable building blocks and runtime services that facilitate the development and use of end-user applications. Network security is incorporated in the design. The application layer includes information searching, collaborative engineering such as co-design, co-prototyping, and electronic commerce.

Numerous technologies and approaches have been recognized in order to support the aforementioned structure. Complex event processing (CEP), the agent-based models approach [15], Sequential Probability Ratio Test (SPRT) [22], artificial neural networks (ANNs) [21] constitute well-known and widespread alternatives.

\section{Operational Level DMN Governance}

This sub phase deals with the processing of the data retrieved during the monitoring phase and the decisions that should be taken and communicated in the responsible network points for easing out any abnormalities identified. As such, the main tasks performed in this phase deal with issues resolution, communication of the necessary actions to the DMN network nodes and coordination of the overall network in order to bounce back into an effective and productive state.

As noted by Douglas and Padula [5], "governance refers to the set of rules, restrictions, incentives and mechanisms applied to coordinate the participants in an organization", while Theurl [24] calls it micro-governance and notes that, under rules, one must include procedures for cooperation, management, decision making, conflict resolution and ways to adapt the operation. Operational Level DMN governance implies the need of control and management actions in real time, which requires the appropriate mechanisms for collecting and analyzing the data from the different nodes in real time (or close to real time).

According to [1], a common mistake performed is the perception that there is direct relation of the behavior and the management activities of virtual organizations to these single organizations. Sydow [23] argues that the management of an interorganizational network implies significant changes to the functions and management practices, compared with those used in hierarchical organizations and corporations. The possibility to optimize the coordination of the value network is better in the single-organization environment, whereas multi-organization environments focus on collaboration and feasible, but not optimal, ways to coordinate the network [19]. Based on the same study, the possibility to effectively manage a value network is also 
dependent on the quality of the available information, and ICT is playing a very important role in this direction, trying to bring the various systems together.

Although many propositions have been made in order to address the network complexity [8], [16], probably the most important interoperability constraint faced today deals with the inability of systems to directly use these standards and build touch points for interacting directly with the other systems. This need is addressed by the introduction of the Enterprise Service Bus (ESB) concept, which is a software architecture model used for interconnecting different software applications in a Service Oriented Architecture [3]. A well-designed ESB for manufacturing applications would be able to bring together the PLM and ERP capabilities of systems, thus allowing governing the network. Adapter modules are responsible for providing a layer of abstraction between the servers and the component business or manufacturing systems (nodes) in the ESB, e.g., ERP, cPLM, product data and workflow systems. To promote interoperability, execution in this type of architecture occurs among component system adapters within the ESB. The component adapters facilitate point integration of component systems by adapting legacy systems and applications and other back-end resources such as databases, ERP, MES (Manufacturing Execution Systems), and PLM, to the ESB so that they can express data and messages in the standard internal format expected by the ESB.

\section{Network Performance Measurement and KPIs Monitoring}

This sub-phase includes measurement of the performance of the DMN by taking into consideration specific methodologies, directives and indicators for measuring and evaluating the effectiveness of the network, not only in operational but also in conceptual and strategic level. The most important business processes are - in general those related to Production procedures, Supply Chain operations, Human and Physical Resources management, Product Development, Sales and Financial Management.

Generally, the challenge in network performance measurement is the necessity to transfer highly complex real-world processes to a simplifying processes model, to derive performance information from the model, and to transfer these results back to the real world [6]. The drawback of the several "traditional" approaches in performance measurement (e.g. Benchmarking, Six Sigma, EFQM, SCOR) is their orientation to single processes or functions, focusing on few certain perspectives, so they are not so appropriate for evaluation in strategic level. In all the recent studies [25], [7], [12], [4], [10], [18] several aspects of collaboration performance and potential performance indicators can be identified. Selected sets of KPIs measuring flexibility, reliability, and prompt-ness/speed are taken as defined in traditional approaches (SCOR, BSC). Westphal et al. [26] goes a step further and proposes a generic structure that organises the different aspects, while it also supports the integration of collaboration performance in existing performance measurement approaches.

In any case, it is obvious that measurement and monitoring of "combined" KPIs is the key for evaluating a DMN's performance and taking strategic decisions for altering the network's structure and/or operation. Ibis Associates [9] also provide a set of the most commonly used KPIs in manufacturing and engineering enterprises. 


\section{$5 \quad$ Network Performance Evaluation and DMN Reformation}

"Network Performance Evaluation" includes the analysis and evaluation of the latter towards deciding on whether a reconfiguration of the network is necessary in order to maximize the anticipated results (e.g. risk/opportunity assessment, optimization of the DMN organizational structure, evaluation of the DMN management approach, inheritance management etc.). Contrary to the "Real Time Data Collection" and the "Network Performance Monitoring" sub-phases, "Network Performance Evaluation" involves considerably the human aspect and relies to a large extent on management experiences previously acquired.

The reconfiguration of the network's organizational structure is possible and justifiable as a result of the fluidity and changing nature of a DMN and should be performed in the light of optimizing the network structure and enabling better accomplishment of its objectives. The type of the DMN organizational structure is interdependent to the DMN management approach, discussed in the following paragraph, while it should also basically determine the framework for knowledge management.

As already outlined, "Monitoring and Governance" is the last phase of the DMN lifecycle, which aims at monitoring and controlling the operation of the network in a continuous way, resulting either in "small and corrective" decisions towards the network's operation optimization or to "larger and structural" changes, which are fed back to the DMN "Network Configuration" phase. Despite the fact that the nature of a DMN is prone to change and evolution, such a network is practically a strategic alliance among enterprises that poses a great deal of advantages for its members, so that it is in their best interest to maintain its operation. Yet, although less likely to occur, one of the possible stages in the DMN lifecycle is the DMN dissolution.

In the unusual event of DMN dissolution, there is a need to plan the transfer of the knowledge collected within the DMN to its members or another entity based on defined agreements. Such knowledge may include devised practices, developed products and processes, warranties, Intellectual Property Rights, knowledge about customers and markets, working and sharing principles, partners' performances, performance metrics, and other information possibly important for future activities [1]. In this case it is necessary to process the information first to obtain an utilizable format instead of transferring all available raw data. As far as network performance metrics and KPIs are concerned, typical processing includes among others the calculation of means, maximum and minimum values as well as standard deviations. The number of measured values and the target values improve the picture. The DMN inheritance management is intended to support future endeavors of the DMN partners in terms of [2]:

- improving their preparedness and thus supporting the faster creation of DMNs;

- making DMNs more effective and reliable in terms of both time and costs and improving or ensuring quality;

- decreasing DMN management efforts through increased trust and strengthened relationships;

- $\quad$ supporting decision-making and tracking of DMN problems or deviations;

- enabling higher chances of success in competitive bidding, because of customer knowledge and closer customer relationships. 


\section{The IMAGINE Project Approach}

IMAGINE ${ }^{1}$ is an R\&D project, funded by the European Commission under the "Virtual Factories and Enterprises" theme of the $7^{\text {th }}$ Framework Programme. The project targets the development and delivery of a novel comprehensive methodology and the respective platform for effective end-to-end management of DMNs in an innovative plug and produce approach, and aims at supporting the emergence of a powerful new production model, based on community, collaboration, self-organization and openness rather than on hierarchy and centralized control.

The DMN lifecycle, as defined by IMAGINE, is structured as an iterative closedloop, network manager assisted methodology that enables automation of repetitive steps, while retaining the flexibility to allow product variants, value adding network re-configurations, and end-to-end processes customizations. The IMAGINE framework relies on end-to-end integrated ICT solutions that effectively enable the management of networked manufacturing supply chains. The IMAGINE solution is market-oriented with focus on value chain streamlining and support for innovative business models. Processes are streamlined looking for the flexibility to adapt to take advantage of the unique capabilities inherent at each individual company, and to adapt easily to changing circumstances and emerging markets.

The three major phases that constitute the IMAGINE Lifecycle are: i) Network Analysis and Configuration that deals with the formation of the DMN upon the receipt of a new order and the validation of its capability to carry out the necessary production ii) Network Design, which focuses on modelling and developing the coordination plan of the various manufacturing processes, and finally iii) Network Execution Management and Monitoring. Network Execution Management and Monitoring aims to include process and production tracking, performance analysis (based mainly on carefully selected KPIs), labour management, resource availability management, movement, storage and tracking of materials, as well as repair adaptation and tuning leading eventually to Network refinement and improvement.

The DMN collaboration platform of IMAGINE will provide the technical backbone to support the proposed life cycle and integrate virtually all the aspects of the virtual manufacturing network and processes.

\section{Conclusions}

As presented in the document at hand, according to current approaches, three consequent key phases are considered in the lifecycle of a DMN: a) Network Configuration, b) Network Design, and c) Network Monitoring and Governance. The present study focused on the last phase which is the most crucial for the operation and the sustainability of the network. It can be taken for granted that, no matter how efficient and effective a Dynamic Manufacturing Network can be, the monitoring and governance of such a multi-disciplinary formation is a real challenge, as poor performance in

\footnotetext{
${ }^{1}$ http: / / www. imagine-futurefactory.eu
} 
management and monitoring could easily cost huge amounts of money and time, while it could even result in the collapse of the network.

As stated above, the last phase of the DMN lifecycle claims the responsibility for monitoring and governing end-to-end process performance and detecting events that may affect the execution of the manufacturing operations. Analyzing process efficiency and effectiveness and aligning processes with enterprise goals and objectives involves reacting to critical business events, correlating event data and updating the, during the Network Design phase defined, key performance indicators (KPIs).

The IMAGINE Project proposes a novel, integrated solution-focused manufacturing environment that involves global supply chain management, product-service linkage and management of distributed manufacturing assets. It enables companies to improve visibility and optimize supply network performance by connecting key people, processes and information across the production lifecycle into a collaborative manufacturing environment, while providing continual refinement and improvement of end-to-end processes through the constant measurement, evaluation and improvement of processes and resource consumption patterns.

Acknowledgements. The research leading to these results has been supported by the EC $7^{\text {th }}$ Framework Programme under the project "IMAGINE - Innovative end-to-end management of Dynamic Manufacturing Networks" Grant Agreement No. 285132.

\section{References}

1. Camarinha-Matos, L.M., Afsarmanesh, H., Ollus, M.: ECOLEAD: A Holistic Approach To Creation And Management Of Dynamic Virtual Organizations. In: Camarinha-Matos, L.M., Afsarmanesh, H., Ortiz, A. (eds.) Collaborative Networks and Their Breeding Environments. IFIP, vol. 186, pp. 3-16. Springer, US (2005)

2. Camarinha-Matos, L.M., Afsarmanesh, H., Ollus, M.: ECOLEAD and CNO base concepts. In: Camarinha-Matos, L.M., Afsarmanesh, H., Ollus, M. (eds.) Methods and Tools for Collaborative Networked Organizations, vol. VIII, pp. 3-32. Springer (2008)

3. Chappell, D.: Enterprise Service Bus. O'Reilly Media (2004)

4. Colotla, I., Shi, Y., Gregory, M.J.: Operation and Performance of International Manufacturing Networks. International Journal of Operations and Production Management 23(10), 1185-1206 (2003)

5. Douglas, W., Padula, A.: Governance and Management of Horizontal Business Networks: An Analysis of Retail Networks in Germany. International Journal of Business and Management 5(12) (December 2010)

6. Eschenbaecher, J., Seifert, M.: Predictive Performance Measurement in Virtual Organisations. In: Camarinha-Matos, L.M. (ed.) Emerging Solutions for Future Manufacturing Systems. IFIP, vol. 159, pp. 299-307. Springer, New York (2005)

7. Graser, F., Jansson, K., Eschenbächer, J., Westphal, I., Negretto, U.: Towards performance measurement in virtual organizations - potentials, needs and research challenges. In: Camarinha-Matos, L.M., Afsarmanesh, H., Ortiz, A. (eds.) Collaborative Networks and their Breeding Environments. IFIP, vol. 186, pp. 301-310. Springer, New York (2005)

8. Hill, T.: Manufacturing strategy: Text and cases, 2nd edn. Palgrave, Hampshire (2000)

9. Ibis Associates, Key Performance Indicators (2011), http: / / www. ibisassoc.co.uk (accessed November 12, 2011) 
10. Jähn, H.: Value-added process-related performance analysis of enterprises acting in cooperative production structures. Production Planning and Control 20(2), 178-190 (2009)

11. KAP, Deliverable 5.1 - Requirements and State-of-the-art for Monitoring, Analysis and Mining of Event Streams (2011),

http: //kap-project.eu/fileadmin/KAP/user_upload/

Deliverables/D5.1.pdf (accessed November 12, 2011)

12. Kaplan, R., Norton, D.: Balanced Scorecard, Boston (1996)

13. Katzy, B., Schuh, G.: The Virtual Enterprise. In: Molina, A., Sanchez, J., Kusiak, A. (eds.) Handbook of Life Cycle Engineering: Concepts, Methods and Tools, pp. 59-92. Kluwer Academic Publishers (1998)

14. Lau, H.C.W., Wong, E.T.T.: Partner Selection and Information Infrastructure of a Virtual Enterprise Network. International Journal of Computer Integrated Manufacturing 14(2), 186-193 (2010)

15. Gou, H., Huang, B., Liu, W., Li, X.: A Framework for Virtual Enterprise Operation Management. Computers in Industry 50(3), 333-352 (2003)

16. Olhager, J., Rudberg, M.: Linking manufacturing strategy decisions on process choice with manufacturing planning and control systems. International Journal of Production Research 40(10), 2335-2352 (2002)

17. Putnik, G., Cruz-Cunha, M.M., Sousa, R., Avila, P.: Virtual Enterprise Integration: Challenges of a New Paradigm. In: Putnik, G.D., Cruz-Cunha, M.M. (eds.) Virtual Enterprise Integration: Technological and Organizational Perspectives, pp. 1-30. Idea Group Inc. (2005)

18. Romero, D., Molina, A.: VO breeding environments \& virtual organizations integral business process management framework. Information Systems Frontiers 11(5), 569-597 (2009)

19. Rudberg, M., Olhager, J.: Manufacturing Networks And Supply Chains: An Operations Strategy Perspective. Omega 31, 29-39 (2003)

20. Salvadori, F., de Campos, M., Sausen, P.S., de Camargo, R.F., Gehrke, C., Rech, C., Spohn, M.A., Oliveira, A.C.: Monitoring in Industrial Systems Using Wireless Sensor Network With Dynamic Power Management. IEEE Transactions on Instrumentation and Measurement 58(9), 3104-3111 (2009)

21. Sari, B., Amaitik, S., Kilic, S.E.: A Neural Network Model for the Assessment of Partners Performance in Virtual Enterprises. The International Journal of Advanced Manufacturing Technology 34(7-8), 816-825 (2006)

22. Singer, R.M., Gross, K.C., King, R.W.: Applications of pattern recognition techniques to online fault detection. In: Probabilistic Safety Assessment and Management Conference (PSAM), San Diego, CA (1993)

23. Sydow, J.: Management von Netzwerkorganisationen: Zum Stand der Forschung. In: Sydow, J. (ed.) Management von Netzwerkorganisationen, pp. 387-472. Gabler, Wiesbaden (2006)

24. Theurl, T.: From corporate to cooperative governance. In: Theurl, T. (ed.) Economics of Interfirm Networks, pp. 149-192. Mohr Siebeck, Tübingen (2005)

25. Westphal, I., Mulder, W., Seifert, M.: Supervision of Collaborative Processes in VOs. In: Camarinha-Matos, L.M., Afsarmanesh, H. (eds.) Methods and Tools for Collaborative Networked Organizations, pp. 239-256. Springer, Boston (2008)

26. Westphal, I., Thoben, K.D., Seifert, M.: Managing collaboration performance to govern virtual organizations. Journal of Intelligent Manufacturing 21(3), 311-320 (2010) 